\title{
Review of practices for keeping people with disabilities in employment: moving beyond the concept of compensation to implement a developmental approach
}

\author{
Gaëtan Bourmaud ${ }^{\mathrm{a}, \mathrm{b}} \&$ Xavier Rétaux ${ }^{\mathrm{c}}$ \\ a AXErgonomie - 2 place de l'église 95810 Grisy-les-Plâtres France \\ ${ }^{b}$ CNAM / TOF / CRTD / Equipe Ergonomie - 41 rue Gay-Lussac 75005 Paris France \\ ${ }^{c}$ AXErgonomie - 6 rue de la chapelle 68118 Hirtzbach France
}

\begin{abstract}
In France, there are strict laws in place to ensure that people with disabilities have access to, and can remain in employment. In this context, many businesses have "group agreements", to support and fund in-house actions in this area. For the last five years, as part of our work as consultant ergonomists, we have carried out over fifty ergonomics interventions for one of our clients to adapt the working environment for persons with disabilities. This paper presents an analysis of our practices to adapt working environment for employees with disabilities by means of a review of these different interventions. This analysis of practices specifically focuses on an issue we consider to be of vital importance: how to get past the concept of an impairment which can be compensated for with technical solutions, a concept in which both French legislation, and the practices of certain professionals working in the field of occupational disability are firmly rooted, and move towards a developmental approach, with the aim of designing an "enabling environment" [2-4,13].
\end{abstract}

Keywords: Review of practices, Persons with disabilities, Developmental approach, Enabling environment

\section{Introduction}

In France, there are strict laws in place to ensure that people with disabilities have access to, and can remain in employment. In line with the position of the $\mathrm{WHO}^{1}$, this legislation specifies that: "Disability, under this present law, designates any limitation in activity or restriction in participation in the life of society, to which a person is subject, in their environment, due to a substantial, long term or permanent alteration to one or more physical, sensory, mental, cognitive or psychological functions, a multiple disability or disabling health disorder." (French law dated " $11^{\text {th }}$ February 2005 " for the "Equal Rights and Opportunities, Participation and Citizenship of People with Disabilities").

${ }^{1}$ WHO: World Health Organisation ${ }^{*}$ Corresponding authors. Emails: gaetan.bourmaud@axergonomie.com, xavier.retaux@axergonomie.
This law emphasises three key principles: equal access to employment; compensation for the disability and universal accessibility.

These three main principles refer to the obligation for employers to take all necessary measures to ensure equality. This law therefore allows companies to draw up an "agreement" to support and fund in-house actions, which makes provision for the implementation of an annual or pluri-annual programme to support disabled workers, including objectives in terms of results, for example: a rate of employment to be reached over the term of the agreement; a recruitment plan; at least two of the following: a training and inclusion plan, a plan for adapting to new technological developments, or a plan for keeping employees who have become unsuited to their position in the company.

It is in this context, that we have implemented, over the last five years, over fifty ergonomics inter- 
ventions for the same client, to adapt working environments for persons with disabilities, as part of an inclusion or employment maintenance scheme. Commissioned by the company's disability taskforce, organised around this "group agreement", and with the involvement of the three people responsible for "access to employment", both the sum of this experience and the way the different interventions have followed on have caused us to question our professional practices, as detailed in this paper.

We will first address the practice of ergonomics consultancy interventions to adapt working environment for disabled workers, as allowed, or indeed imposed by French legislation. We will also present the specific context in which our interventions took place: the company, its disability taskforce and our working relationship with the people responsible for this issue. The review of the interventions proposed covers two levels of analysis:

- On the first level, we will present a descriptive review: a primarily quantitative analysis, which aims to broadly categorise these interventions (by profession, type of disability etc., as well as the adjustments actually implemented, in order to draw out both similarities and differences, common or specific levers etc.);

- On the second level, we will aim to use other forms of categorisation to question our practices (our intervention methodologies, and even the ideology behind our practices). We will specifically look in detail at one of our interventions which we consider to be a textbook example, in terms of the objectives we have for our professional practices. In conclusion, we will try to draw out the salient points of this intervention by integrating points of comparison from other interventions.

This analysis of practices specifically focuses on an issue we consider to be of vital importance: how to get past the concept of an impairment which can be compensated for with technical solutions, a concept in which both French legislation, and the practices of certain professionals working in the field of occupational disability are firmly rooted, and move towards a developmental approach, with the aim of designing an "enabling environment" [2-4,13]. This is the focus of the last section of this paper.

\section{Background to practices}

Under the legal framework set out in the introduction, and according to the institutions responsible for ensuring its application, an ergonomics study to adapt working situations to disabled employees should include (according to AGEFIPH ${ }^{2}$ ):

1. "An evaluation of functional capacities: the aim being to identify the person's potential and degree of autonomy, and the limitations or possible risks resulting from their impairment, with a view to drawing up or validating a career plan, or a solution for keeping them in employment, or to offering access to employment or training.

2. The identification of the compensation techniques to be implemented in light of the situation assessed: this should allow the disabled employee and the ergonomist to carry out a needs analysis and make recommendations concerning the resources and solutions required to develop the disabled employee's autonomy, and to accomplish the different phases to support their plans to gain access to, or to remain in employment."

\subsection{Occupational disability and ergonomics}

The practices of ergonomics consultants aiming to adapt working situations for disabled employees are therefore bound by this vision, both by the emphasis on the evaluation of the remaining functional capacities and incapacities, and the focus on compensatory measures: "The person with disabilities has the right to compensation for the consequences of their disability, whatever the cause or nature of their impairment, their age or lifestyle" (Law dated "11th February 2005"), as shown in Figure 1.

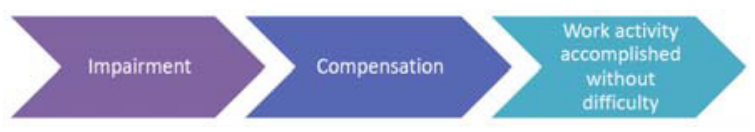

Figure 1: A reductive vision of the compensation principle.

In the final section of this paper, we will present our critical analysis of this approach.

\footnotetext{
${ }^{2}$ AGEFIPH is the National Association of Management of the Fund for Professional Insertion of Disabled People (www.agefiph.fr).
} 
Furthermore, we have observed that generally speaking, the first dimension considered when seeking to compensate for a previously assessed impairment, seems to be the technical one. From our point of view, this is a simplistic view of the principle of compensation for disability.

However, the action taken should be multidimensional, and two further dimensions should be added to this "Technical/Equipment"3 dimension:

- "Technical" dimension: furniture, computer equipment, etc.

- "Organisational" dimension: tasks, working hours and duration, etc.

- "Individual" dimension: training, journey to and from work, rehabilitation, work/life balance, psychological follow-up etc.

Seeking to affect each of these three dimensions requires a more comprehensive approach to the working environments of the employees concerned, as well as the disabling situation ${ }^{5}$ :

- The employee's workstation: furniture, computer equipment, etc.

- The employee themselves: their difficulties, their skills, their future, etc.

- Their actual work activity at the workstation: activity, movements, cooperation with colleagues and the tools/equipments used, etc.

- The work organisation in the company: tasks, working hours, etc.

- Life outside of work: in particular the influence of their professional/personal life, journeys, orthoses etc.

Another constraint which influences practices in terms of ergonomics interventions to adapt working environments for workers with disabilities: They are designed to be accomplished over a short period (usually 3-5 days). The conditions for their funding on the one hand and how they are constructed locally on the other (mainly in terms of the social and methodological dimensions) are therefore particularly stringent.

\footnotetext{
${ }^{3}$ Throughout this paper we will use speech marks to clearly designate the dimension concerned.

${ }^{4}$ The "Technical/Equipment" dimension includes the different physical adaptations, those aiming to improve accessibility and the provision of human help (when technical solutions cannot be implemented).

5 The "disabling situation" concept presents a disability as the result obtained when a human being, with their capacities, comes into contact with an environment, with its demands
}

\subsection{The company and its disability taskforce}

The company for which we carried out the different interventions reviewed in this paper is one of France's major banks, composed of branches for professional and private customers, back-office services and various subsidiaries, etc. It employs over 150,000 employees, working in the different entities described above, and 3,000 of these are persons with disabilities. Its group agreement commits the company to recruiting almost 150 disabled employees a year.

In order to do so, the disability taskforce at national level is composed of several disability officers. Our interventions were overseen by three of these disability officers. This allowed us to develop a working relationship of mutual trust which is unusual and which largely facilitated the implementation of our interventions.

This very close relationship notably allowed us to establish, by common accord, a service provider contract allowing us to implement each of our interventions as a package, i.e. with no demand analysis, considered in ergonomics to be an essential step in the process [5]. It should also be noted that in most cases, our interventions cover, an initial study phase, to understand the situation and formulate our recommendations, and a follow-up phase, to support and guide the person through the changes in their working environment. The participation of a number of key stakeholders is vital for the success of the interventions implemented in this company:

- The employee concerned;

- One of the disability officers;

- The occupational physician;

- The management (this may be the person's line manager, or cover several levels of the hierarchy);

- The ergonomist.

Depending on the precise nature of the intervention, other stakeholders may be mobilised such as: specialist doctors and other medical specialists (for hearing prostheses for example), the in-house logistics officers and other in-house technical services, the company's suppliers and the ergonomist's network, etc. 


\section{First level review: Descriptive approach of our interventions}

In this sub-section, we will present a descriptive review of the results of our interventions.

The vast majority of cases we were presented resulted in an actual intervention: of the 53 case files opened, 49 resulted in an intervention and four ${ }^{6}$ did not go beyond the recommendations stage.

\subsection{Types of impairments and professions}

These interventions fall under several main categories covering a wide diversity of impairments and difficulties (See Figure 2: distribution of case files according to the type of impairment): back problems represent 12 cases; 11 cases concerned sensory impairments, notably 8 of whom were visual impairments and upper-limb impairments represented 8 cases (including 3 hand impairments).

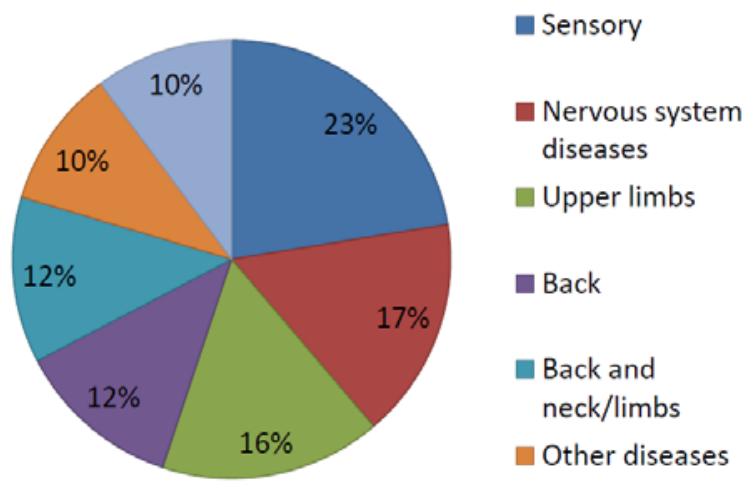

Figure 2: Distribution of case files according to the type of impairment.

These interventions also concerned a wide variety of positions (see Figure 3).

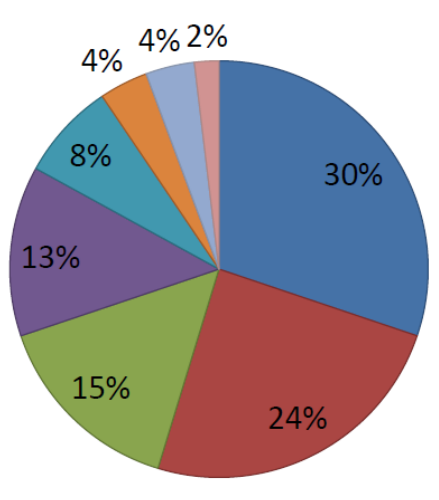

Employees Back office

Other nonagency

Branch Advisor

Branch Receptionist

口 IT Project Manager

Branch Assistants

Branch Manager

Figure 3: Distribution of case files according to the type of position held

This data reveals a wide diversity in the working environments within the company and a wide range of impairments: our data is certainly situated, but far from homogeneous and therefore potentially apt for generalisation.

\subsection{Types of adaptations}

Figure 4 (1) shows that "Technical/Equipment" adjustments are quasi systematic, and "Organisational" adjustments (2) are put into place in half of the cases. "Individual" solutions are much rarer.

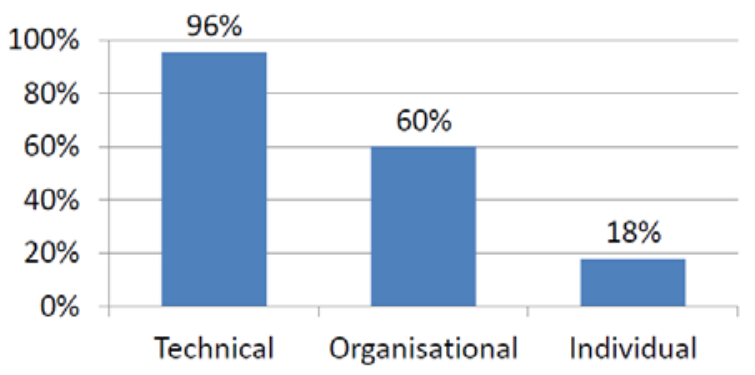

Figure 4: Distribution of interventions according to the type of solution implemented.

In our opinion the less frequent implementation of "Organisational" adjustments can be explained by the following factors:

1. the management is often resistant to any kind of interference in its prerogatives, including the work organisation;

\footnotetext{
${ }^{6}$ The four case files which did not result in an intervention (notably due to the death or retirement of the employees in question) and which have not been acted upon to date are not taken into consideration here.
} 
2. the work organisation is often highly structured and inflexible: there is very little room for maneuver in terms of working hours, task assignment etc.

"Individual" solutions also seem to be infrequently implemented. The overlap between people's working lives and their private lives is however a well documented phenomenon. The problem of "tiredness" is a particular issue for people in disabling situations who often use their time outside of work to recover. In France, there is a strict legal separation in place, designed to protect people's private lives, but which often stops companies from taking action in this area. Moreover, the budgets allocated to adjustments of this nature are strictly confined to the corporate sector.

\section{Second level review: a reflective analysis of our professional practices}

This section of the paper calls our practices into question using a different, more qualitative approach. We will therefore focus on one of our interventions in particular which we consider to be exemplary in terms of the objectives of our professional practices. We will then aim to draw out the salient points from this intervention by integrating points of comparison with other interventions implemented.

\subsection{Presentation of a "textbook" case}

We are going to focus in detail on one of the interventions carried out for this company. Of all the interventions carried out it is the one which best illustrates the approach we wish to promote through this paper. It shows just how important it is to think through the work environment of the employee in a disabling situation, in its entirety.

\subsubsection{Background information}

Mr. B. works as an operative in the mail department at this bank's head office. The mail department is tasked with sorting and "distributing" the mail (i.e. "ensuring the mail reaches the right person as quickly as possible”). The department handles a volume of 4000 - 5000 items per day.

The mail department is made up of 12 people including one manager: 8 of these 12 employees are responsible for sorting and distributing the items and 6 of them work shifts (on a weekly rotation with the following working hours: $6.45 \mathrm{am}-12.30 \mathrm{pm}$ or $12.30-7 \mathrm{pm})$.

Mr. B. is one of the latter. He was 52 years old at the start of the intervention and has worked in the department for over 30 years.

He went to the company's occupational physician with shoulder pain: a surpraspinatus tendinopathy of the right shoulder with loss of strength during muscle testing.

An ergonomics intervention was subsequently requested to look at both Mr. B.'s specific situation and the overall situation for employees in the mail department.

\subsubsection{Stages of the intervention}

The first measure was to set up a project group to steer the intervention. A group of permanent members made up the core of the project group:

- The mail department manager,

- The occupational physician,

- A disability taskforce representative,

- 2 ergonomists.

Other stakeholders participated on a more or less regular basis, including the mail department workers, management and staff representatives, representatives from other departments such as communications, support services, and real estate etc. In order to involve the different stakeholders, we carried out interviews with each of them, in order to clearly understand what we could expect of them.

The objective for this intervention was to understand the operators' work with the aim of drawing up an initial set of hypotheses regarding the contributing factors for $\mathrm{MSD}^{7}$, looking at: biomechanical constraints (repetitiveness, strength, duration and speed of the movement, etc.); postural constraints (static work, load lifting, etc.) and other risk factors: the psychosocial, organisational and cognitive dimensions of the workers' work.

In order to do this, an analysis of the work activity was carried out (interviews and open observations of the work).

A pre-diagnostic established the main contributing factors for MSD as: Age, posture (type and duration), materials handling, managing different constraints (incorrectly addressed mail, variations in the volume and intensity of work). This pre-diagnostic was then verified by means of more detailed observations.

\footnotetext{
${ }^{7}$ MSD: Musculoskeletal Disorders.
} 


\subsubsection{Seeking/construction adaptation solutions First objective: Limit effort and at-risk postures for all employees}

- On the "Individual" level: on the basis of the actual work activity observed and described, a training course on preventing the risks related to physical activity in the work, aimed to objectivise the harmfulness of the movements carried out. According to the employees themselves, the training was not particularly effective in the long term. However, as the training was deployed rapidly, it did teach them about postural risks and demonstrated the interest of study. It was then necessary to give them the time and space to put this knowledge into practice, which of course takes much longer.

- On the "Technical" level:

- Change of flooring in the mail department: this was done in order to improve its general condition and ensure the trolleys could be moved smoothly around the department. The flooring in place was soft and in poor condition making it difficult to maneuver the heavier trolleys.

- Actions regarding the loads handled: these actions aimed to standardise the loads handled, by providing employees throughout the company with standard packages for sending documents. This was to avoid the surprisingly common phenomenon of employees sending large boxes full of documents, some weighing more than 25 kilograms.

- $\quad$ Replacing the large baskets used to transport items, in order to avoid at-risk postures when unloading: the use of these baskets obliges the person to bend over almost to floor level, with their legs straight. These were replaced with trolleys with side openings.

- On a mixed "Technical + Organisational" level:

- Layout of the item distribution areas: installation of new lockers (with a "mirror" organisation reflecting the actual spatial location of people and departments), and sorting tables etc. to replace the existing furnishings.

- Layout of the "emergency items" office: Mr. B.'s workstation was transferred to a new space shared with two other workers as part of a move to increase the variety of tasks assigned to him. As Mr. B. is called upon to work at either workstation to replace his col- leagues (a specific task is carried out at each workstation), all the workstations were adapted to limit at-risk postures.

Second objective: Limit the cognitive load

- On the "Organisational" level:

- Correctly addressed mail: the issue of incorrectly addressed mail has been tackled through a number of internal interventions. The communications department in particular has been solicited to inform staff about the correct addressing of mail to facilitate the work of the mail department, and ensure external contacts were also given addresses in the correct format. However, employees in the mail department, do not feel that these initiatives have had any significant impact, although of course their effectiveness can only really be judged in the long term.

- On the mixed "Technical + Organisational" level:

- Layout of the item distribution areas: installation of new lockers and sorting tables etc. to replace the existing furnishings.

- Installation of a pre-sorting workstation with the aim of filtering out incorrectly addressed mail and re-addressing it prior to distribution.

Third objective: Re-organising the work and working patterns

The analysis of Mr. B.'s activity showed that he was carrying out a large number of tasks, considerably more than his colleagues. In light of this observation and with Mr. B.'s consent and participation, we decided to implement 3 main actions:

- On a mixed "Technical + Individual" level: change his working hours and remove him from the team work, with the dual aim: 1) that he no longer has to work shifts, and 2) that he is no longer included in the collective work objectives which meant he felt obliged, out of respect for his colleagues, to do more than his physical condition allowed.

- On the "Organisational" level:

- Increase the variety of tasks he must accomplish in order to limit repetitive movements: the main difficulty being to create a workstation which corresponded to his needs and capabilities. This workstation was intended to give him more time to manage his tasks.

- Provide him, finally, with a workstation at which he can work seated, to allow him to sit down when he feels the need. 
Mr. B. subsequently saw his levels of tiredness decrease, in particular when he stopped working shifts. Today, he is still a very active member of the department, but organises his tasks as he sees fit, according to the state of his shoulder. When he helps his colleagues working in the teams, he works under less strenuous conditions thanks to the "Technical" adjustments implemented.

Several months later, as noted by the occupational physician, the employee's health had considerably improved and he today (several years after this intervention) is showing signs of remission.

\subsection{Comparative approach to our interventions in light of Mr. B. 's case}

We have found some of the other interventions we have implemented to be far less satisfactory in terms of the range of adaptations put into place, how the project was steered and the role played by the stakeholders involved etc.

It is not possible to detail all of these interventions in this paper, but we would like to present certain points of comparison.

\subsubsection{Other cases}

Mrs L. was the victim of a road traffic accident in 1989. She suffers from hearing loss (particularly evident in noisy environments, with tinnitus), impaired vision (total loss of vision in the right eye), occasional loss of balance, and problems with her memory and tiredness.

This employee worked for a long time at the reception of a bank branch, work she found particularly difficult due to her sensory impairments. For several years, she has had no contact with customers following a recommendation made by the occupational physician. She has since been assigned "crosscutting" tasks, mainly secretarial duties for all departments across the branch. She does not have a fixed position, nor a job description as all secretarial positions in the branches have been cut.

We were asked to intervene as Mrs L. often works alone in the basement, filing documents in the archives. We tried to adapt her movements, in particular the vertical movements and to provide her with an alarm for use in the event of a fall. We also sought to reduce her tinnitus by means of a hearing aid. The occupational physician opposed this proposition. The management did not want to address the issues of the non-existent job description and the lack of a fixed workstation. Given these difficulties, the employee became afraid that the current compromise would be revoked if she entered into conflict with her line management and she asked us to terminate the intervention.

We feel that this case perfectly illustrates the need for all stakeholders in the working environment to be fully involved. Despite our efforts, we were unable to bring the intervention to a satisfactory close and had to settle for a number of physical adaptations.

\subsubsection{Review}

On the basis of the examples presented above, the table in Table 1 sets out the links between the methodological imperatives and the objectives of the intervention.

Table 1: Links between methodology and objectives

\begin{tabular}{|c|c|c|c|c|c|}
\hline $\begin{array}{c}\text { Dimension } \\
\text { for adaptation }\end{array}$ & $\begin{array}{c}\text { Demand } \\
\text { analysis }\end{array}$ & $\begin{array}{c}\text { Interviews with the } \\
\text { employee and observa- } \\
\text { tions of their activity } \\
\text { and participation of } \\
\text { colleagues }\end{array}$ & $\begin{array}{c}\text { Interviews with } \\
\text { and participation of } \\
\text { management (and } \\
\text { staff representatives) }\end{array}$ & $\begin{array}{c}\text { Involvement } \\
\text { of technical } \\
\text { support services }\end{array}$ & $\begin{array}{c}\text { Local } \\
\text { feedback and } \\
\text { discussion }\end{array}$ \\
\hline $\begin{array}{c}\text { Organisa- } \\
\text { tional }\end{array}$ & Required & Required & Variable & Required \\
obligatory & Requigled & Required \\
\hline Individual & Required & Required & Non-obligatory & Non-obligatory & $\begin{array}{c}\text { Non- } \\
\text { obligatory } \\
\text { obligatory }\end{array}$ \\
\hline
\end{tabular}

$\underline{\text { Table 1: Links between methodology and objectives }}$

From this, we can see that:

- If the objective of the intervention is to implement a purely "Technical" compensation, the only requirements are for interviews with the employee and observation of their activity, as well as the involvement of technical support services (IT, for example). The duration of the intervention can therefore be 
reduced to a few days. As in the case of Mrs L., the implementation of technical measures to reduce the negative impact of work on the person's health, is not in itself sufficient to reposition the employee in a satisfactory working environment.

- However, "Technical" adaptations do not only apply to the employee's workstation (as in the case of Mr B.), and modifications to the organisation of work require the involvement of the person's colleagues and line management (and possibly staff representatives), and therefore an understanding of the individual and collective activity, and the overall organisation of work. This often takes considerably more time (two or three times as long). The majority of our interventions required the integration of these dimensions.

- Intervening in the "Individual" dimension requires the employee to have a very good understanding of our objective: it is important to progress cautiously when addressing issues considered to be part of people's private lives ${ }^{8}$.

We therefore propose considering the different dimensions on which action should be taken in terms of possible combinations, mixes and interdependencies. Indeed, these dimensions should not be tackled separately using a sequential approach.

In our opinion, these dimensions present systemic characteristics which must be taken into account. A system is generally characterised by four fundamental concepts [1,7-10]:

- interaction: the key aspects of a system are the relationships between its different components; these relationships take different forms, such as interdependency, causal relationships, feedback, inter-retroactions, etc.;

- holism: this is much more than the sum of the system's components. In addition it takes into consideration the concept of "emergences", proposed by Morin to emphasise "the qualities and properties born out of the organisation of a whole" [10], these "emergences" present "a new character in comparison with the qualities or properties of each component considered in iso-

\footnotetext{
${ }^{8}$ Other professionals, notably occupational therapists, are highly active in this area, using other methods and skills.
}

lation, or differently inter-related within a type of system" [7];

- organisation: this concept is both a state and a process, "the organisation ensures a relative solidarity between these liaisons and ensures the system has a certain level of sustainability" [7]. In this case the key issue is how the components are set out and related;

- complexity: a concept developed by Morin who - notably in his work published in 1999, entitled "The intelligence of complexity" coauthored with Le Moigne - declared his hostility to reductionism and atomism, which he believes to be far too pervasive in traditional scientific research, in favour of complexity - considered to be "more of a logical concept than a quantitative concept" [10] "whilst admitting that it is impossible to fully understand and record this wealth in its entirety" [1].

These different system characteristics developed herein, seem to concord with the relationships that are, or should, exist between the different dimensions for adaptations.

The Figure 7 presents the systemic structure we believe should exist between the different dimensions involved in adapting working environments for workers with disabilities.

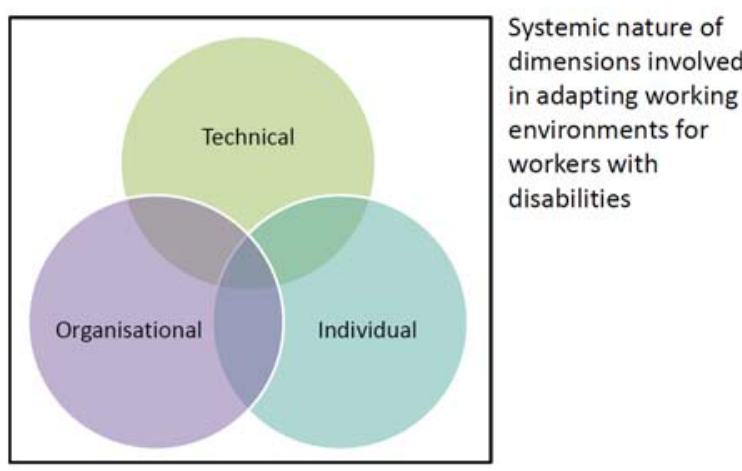

Figure 7: The systemic organisation of the dimensions involved in the adaptation of working environments of employees with disabilities

\section{Proposed professional practices to adapt the working environments of employees with disabilities}

In this final section, by way of the final discussion, we will detail a series of proposals which aim to go 
beyond the objective of providing technical compensation for a simple impairment, and move towards a developmental approach, with the aim of designing an "enabling environment" [2-4,13].

\subsection{Moving towards the use of constructive ergonomics to adapt the working environments of employees with disabilities}

The basic process, as laid out in law, consists of carrying out an evaluation of the employee with disabilities' functional capacities and incapacities, and finding a way of compensating for the consequences of their disability refers us clearly back to a defensive (or purely corrective) vision of professional practices in ergonomics, built around the following notion: protect the employee by adapting their workstatio ${ }^{9}$. This objective has several disadvantages, including the following:

- the proposed adaptations can only ever be short term solutions: they do not take into account the constantly changing dynamic of disabling situations and of work, notably in terms of the evolution of impairments and organisational changes,

- in an even worse scenario, caricatured representations of disability [6] can lead to a culture of stopgap solutions.

In contrast to this defensive ergonomics, we believe in constructive ergonomics which aims to develop "opportunities for professional development and the construction of health" [6], or to put it another way, "the power to act" [12], and a capable subject [11]. Two complementary approaches to health seem to coexist: "The first is corrective and preventative. It aims to compensate for individual impairments and avoid situations which generate negative effects. The second is constructive. The aim being to develop the construction of health." [4].

Falzon has proposed the creation of an enabling environment as a tangible objective for this constructive ergonomics, this environment is defined from these three perspectives:

- From a preventative perspective: an enabling environment is one with no harmful impact on the individual and which maintains their future capacity to take action. This does not only concern the detection and prevention of risks, but also the preservation

\footnotetext{
${ }^{9}$ S. Caroly: oral presentation at the 3rd French Congress on MSD, Grenoble, France, 2011.
}

of the person's physical and cognitive capacities.

- From a universal perspective: an enabling environment is one which takes into account inter-individual differences (in terms of anthropometric characteristics, but also age, gender and culture) and which compensates for individual impairments (relating to ageing, illness and incapacity).

- From a developmental perspective: an enabling environment is one which allows people to develop their capacities. An enabling environment contributes to the cognitive development of people, teams and organisations.

\section{Conclusion}

This paper is built around an analysis of the professional practices for ergonomics consultancy interventions to adapt working environments to workers with disabilities.

We have observed that French legislation limits these practices in several ways - the conditions for obtaining funding, the social or methodological construction of the intervention, and in particular through the expectation that the impairment can be neutralised by providing a compensatory solution (usually technical), it encourages the implementation of very narrow actions (defensive or corrective vision).

Our interventions are implemented as part of a different approach: we believe an ergonomics intervention should adopt a constructive vision. In this context, the enabling environment, as proposed by Falzon, seems particularly well suited to our very specific objective, of professional practices for ergonomics consultancy interventions to adapt working environments for workers with disabilities

One important outcome from this review of almost 50 interventions, carried out for the same client, and therefore in comparable conditions, is that the possibility of creating an enabling environment for workers with disabilities depends far more on the aspects listed below, than simply on the suitability of the equipment recommended:

- The details in the intervention contract: time available, deadlines and how the intervention will be implemented in the company,

- How the project will be implemented: participatory approach or not, 
- The dimensions actually engaged by the adaptations implemented: "Technical", "Organisational" and/or "Individual", and the consideration, and even consolidation of their systemic nature,

- The organisational flexibility: existent or not

\section{References}

[1] D. Durand, La systémique, Paris, PUF, 2002.

[2] P. Falzon, Ergonomics, knowledge development and the design of enabling environments. Proceedings of the Humanizing Work and Work Environment HWWE'2005 Conference, December 10-12, Guwahati, India, 1-8, 2005.

[3] P. Falzon, Enabling environments and reflective practices. ABERGO'2006, 14th ABERGO Congress, Curitiba, Brésil, 29 octobre- 2 novembre, 2006.
[4] P. Falzon and V. Mollo, Para uma ergonomia construtiva: as condições para um trabalho capacitante. Laboreal 1 (2009), 61-69.

[5] F. Guérin, A. Laville, F. Daniellou and J. Durafourg, Understanding and transforming work, Lyon, ANACT, 2007.

[6] F. Guérin, Pluridisciplinarité et prise en compte de la diversité des populations au travail, SELF, 2006

[7] J.C. Lugan, La systémique sociale, Paris, PUF, 1996.

[8] E. Morin, La nature de la Nature, La Méthode, Tome 1, Paris, Seuil, 1977.

[9] E. Morin, Les idées, leur habitat, leur vie, leurs mœurs... La Méthode, Tome 4, Paris, Seuil, 1991.

[10]E. Morin and J.L. Lemoigne, L'intelligence de la complexité Paris, L'Harmattan, Coll. Cognition \& Formation, 1999.

[11]P. Rabardel and P. Pastré, Modèles du sujet pour la conception. Dialectiques activités développement, Toulouse, Octarès. 2005.

[12]P. Ricoeur, Soi-même comme un autre, Paris, Seuil, 1990.

[13]A. Sen, Development as freedom. Oxford: Oxford University Press. 1999. 